\title{
Characterization of Photovoltaic Panels by means of Thermograph Analysis
}

\author{
Noe Samano, José Alfredo Padilla-Medina, and Nimrod Vázquez \\ Electronics Engineering Department, Technological Institute of Celaya, 38010 Celaya, GTO, Mexico \\ Correspondence should be addressed to Nimrod Vázquez; n.vazquez@ieee.org
}

Received 26 March 2016; Accepted 25 May 2016

Academic Editor: Prakash Basnyat

Copyright ( 2016 Noe Samano et al. This is an open access article distributed under the Creative Commons Attribution License, which permits unrestricted use, distribution, and reproduction in any medium, provided the original work is properly cited.

\begin{abstract}
Solar panels have become attractive in order to generate and supply electricity in commercial and residential applications. Their increased module efficiencies have caused not only a massive production but also a sensible drop on sale prices. Methods of characterization, instrumentation for in situ measurements, defect monitoring, process control, and performance are required. A temperature characterization method by means of thermograph analysis is exposed in this paper. The method was applied to multicrystalline modules, and the characterization was made with respect to two different variables, first a thermal transient and second a characterization with respect to the current. The method is useful in order to detect hot spots caused by mismatch conditions in electrical parameters. The description, results, and limitations of the proposed method are discussed.
\end{abstract}

\section{Introduction}

The energy availability in photovoltaic (PV) panel strongly depends on temperature and solar irradiation [1]. Actually, the temperature is one of the main factors which affect seriously the efficiency of solar cells. It is well known that the generated voltage with a solar cell varies with temperature [2]. Dependence on the temperature in a typical PV module characteristic is illustrated in Figure 1.

When temperature increases, the generated voltage decreases. Apart from this temperature effect on the cell voltage, there exists another phenomenon which is related to the temperature known as a "hot spot." A hot spot is a specific well-located region with the higher temperature than the other parts of the cell. While temperature value causes voltage affections, the hot spot phenomenon causes a wide variety of cell problems, as lower efficiency and physical damage.

A thermal transient analysis is reported in the literature [1]: such study was obtained by registering the temperature for a single amorphous silicon module and a couple of monocrystalline modules every minute after a change in environmental conditions. Although the main purpose of this paper was not transient thermal characterization, authors used this for explaining the effect of the module heat in a capacitance during described conditions.
This reported method [1] began by the whole covering of the module in order to reach the equilibrium temperature with the environment. Once steady state temperature is reached, the module was uncovered and a measure of temperature was taken every minute with the aid of thermocouples. Measures were recorded during a period of 24 minutes. Results are shown in Figure 2.

A hot spot may be produced due to the next three reasons: a shadow projected in the module [3-5], a mismatch condition between cells [6-8], or a manufacturing defect [9-11].

Traditionally, the cells in a module are connected in series, and the current at the maximum power point $I_{\mathrm{mpp}}$ becomes critical [12]. When a cell in a serial string produces less power than the rest (due to a hot spot), the maximum power of the string cannot match the maximum power of that "poor" cell. This means that the cells cannot give more energy to the output load, although they are able to produce it.

Therefore, the generated current on excess by any "good" cell is forced to circulate through the internal diode by itself. When module works near short-circuit condition, then voltage may exhibit this as a "poor" cell. In these circumstances, the cell dissipates power instead of generating it.

Hot spots detection is important because it is easier for problem identification or finding photovoltaic module defects. Once a hot spot is detected in a module or array, it 


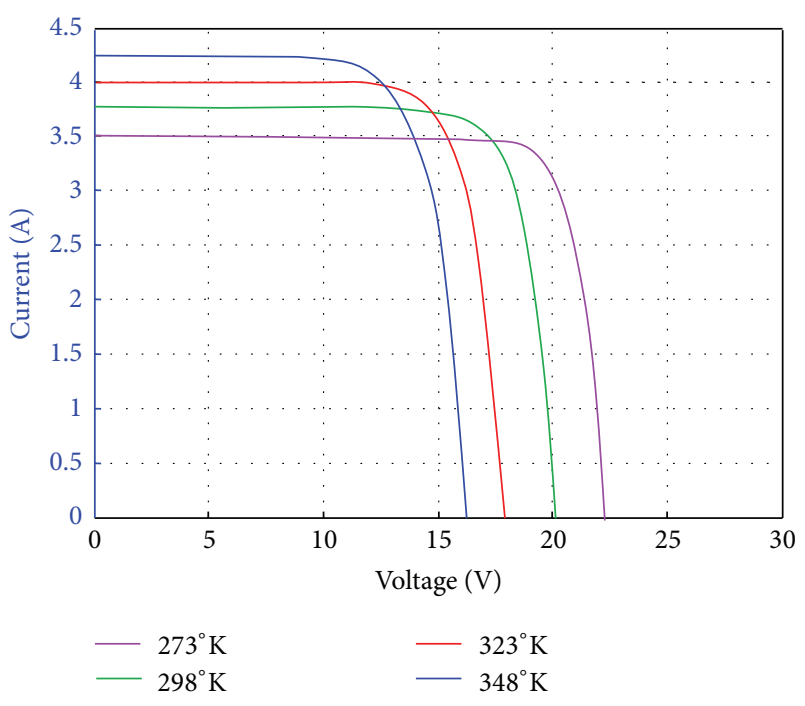

FIgURE 1: Typical PV solar curve and the effect of temperature.

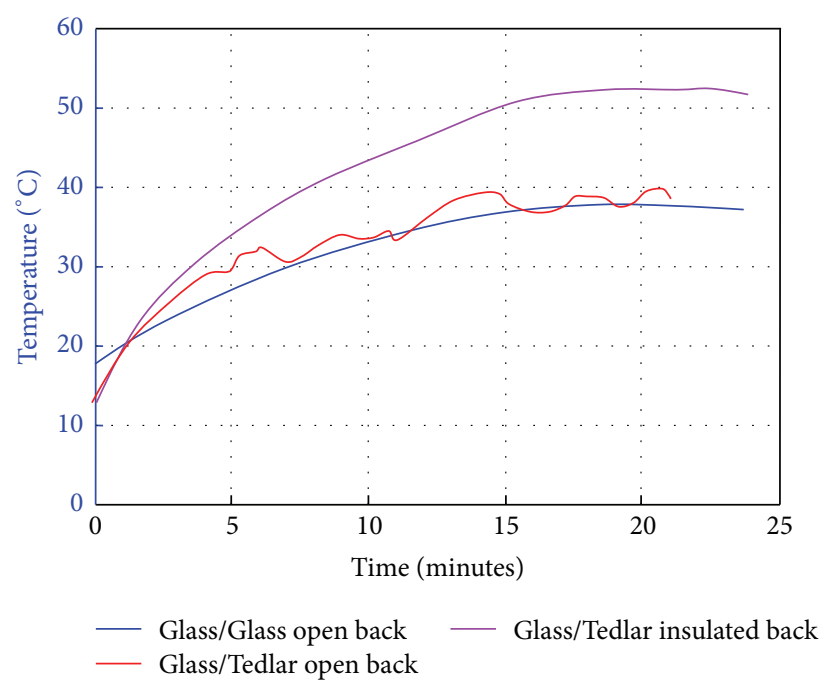

FIgURE 2: Transient of three PV modules as shown in [1].

is evident that an amount of the total power produced by the array is being dissipated in that cell instead of the output load.

Since temperature and hot spots problems are the main factors which affect photovoltaic modules, research on this issue has become important, in order to have a better understanding of these phenomena and, therefore, improve PV system designs.

The PV panel's characterization by means of thermograph analysis for in situ measurements, defect monitoring, process control, and performance is proposed in this paper. Technique on infrared temperature measurement is used for detecting hot spots and establishing the thermal behavior of solar cells.

This paper focused on characterizing thermal behavior. Thermal transients in PV panels were studied at first; and, later, temperature characterization with respect to the module current was made. These two studies allow us to detect and identify the existence of hot spots in the solar module.

The paper is organized as described next: some facts of PV panels are mentioned in Section 2; the work bench for the characterization is detailed in Section 3; in Section 4, the thermal transient is discussed; the current characterization is presented in Section 5; and some final conclusions are given at the end.

\section{Model and Facts in PV Panels}

When a PV module is under the sunlight, it produces energy. When the generated energy is not required, it is consumed as heat by the panel itself, since the PV panel is not operating at the maximum power point, its life time is deteriorated no matter if energy is not delivered. It has to be kept in mind that the possible coldest temperature is reached once the PV panel is operating at the maximum power point.

The hot spots existence in a PV panel decreases the life time for cells $[13,14]$; also, as a consequence, the amount of generated energy becomes reduced. The effect of a hot spot is similar to the PV panel behavior under partially shaded areas $[15,16]$, so that multiple maximum power points start to appear, which seriously affect energy production.

A simplified model for the PV panel is found in [16]:

$$
i_{\mathrm{PV}}=\lambda I_{\mathrm{sc}}-\lambda I_{s}\left(e^{\left(q v_{\mathrm{PV}} / A K T\right)}-1\right),
$$

where $A$ is the ideality factor of the diode, $K$ is the Boltzmann constant, $q$ is the electron charge, $\lambda$ is the percentage of irradiance $(1=100 \%), I_{\mathrm{sc}}$ is the short-circuit current of the PV panel, $I_{s}$ is the saturation current of the diode, $T$ is the temperature of the ambient in ${ }^{\circ} \mathrm{K}, v_{\mathrm{PV}}$ is the voltage of $\mathrm{PV}$ panel, and $i_{\mathrm{PV}}$ is the current of PV panel.

It should be noticed that the only variables to be considered are the irradiance, the temperature, the cell voltage, and current, once the PV panel has been built. The other terms are constants. The PV panel power is then

$$
p_{\mathrm{PV}}=v_{\mathrm{PV}}\left[\lambda I_{\mathrm{sc}}-\lambda I_{s}\left(e^{\left(q v_{\mathrm{PV}} / A K T\right)}-1\right)\right] .
$$

The maximum power point may be obtained by making the derivative equal to zero, and neglecting the irradiance and temperature variations, the next equation is obtained:

$$
\begin{aligned}
& \frac{d}{d t} p_{\mathrm{PV}} \\
& \quad=\left(\lambda I_{\mathrm{sc}}+\lambda I_{s}-\left(\lambda I_{s}+\frac{q v_{\mathrm{PV}}}{A K T}\right) e^{\left(q v_{\mathrm{PV}} / A K T\right)}\right) \frac{d}{d t} v_{\mathrm{PV}} .
\end{aligned}
$$

From this last expression, it may be deduced that the maximum power point occurs at specific panel voltage $\left(v_{\mathrm{PV}}\right)$, and the value depends on the construction of the PV cell; then, if a mismatching of cells during construction could happen, the maximum power point would be different and, therefore, a cell temperature variation would also be registered between cells. This is demonstrated by the characterization proposed in this paper. 


\section{Work Bench and Specifications}

The analysis was made for two mc-Si modules with the following characteristics:

(i) Module type 17(110) P1470X680, of Yingli Solar.

(ii) Peak power $110 \mathrm{~W}$.

(iii) Peak voltage $17.5 \mathrm{~V}$.

(iv) Peak current 6.3 A.

(v) 36 cells connected in series.

(vi) Glass top surface.

(vii) Polymer rear surface.

Both modules were mounted in a structure oriented $20^{\circ}$ to the south, in correspondence with the latitude of the installation place.

An infrared camera was used in order to measure the temperature. It was able to detect wavelengths from $7.5 \mu \mathrm{m}$ to $13 \mu \mathrm{m}$ in the region of the far infrared.

Since the front surface of the modules is reflective, the using of the rear surface of the module is a better choice. The temperature on the front side was compared with temperature on the back side of the module by using an infrared thermometer; it was found that practically both data sets have the same value. When thermographs are taken at the back side, it is avoided to have the shadows which normally occur on the front surface of the module due to weather conditions.

A temperature gradient between the back surface and the cell was considered since the temperature measured on the back surface of the modules is not exactly the actual temperature of the cells. Particularly for mc-Si cells in thermal equilibrium, irradiance is near to $1000 \mathrm{~W} / \mathrm{m}^{2}$, wind speed is less than $3 \mathrm{~m} / \mathrm{s}$, and the temperature gradient between both surfaces is about 2 or $3^{\circ} \mathrm{C}$, which may just be added as an offset [3].

The thermographs were taken at $1 \mathrm{~m}$ distance from the back surface because this is the maximum distance, at which the camera was able to focus clearly. This limitation, added to the lens of $17 \mathrm{~mm}$ connected to the camera, made reading the temperature of the whole module in a single image impossible; for solving this issue, 36 cells from the module were measured in order to complete the module thermograph. According to this configuration, only a couple of cells fitted perfectly in the view field from the camera.

The two modules were operated at three different operating points in order to detect the anomalies in the temperature distribution. Then, the thermographs were taken, when the modules generate $6 \mathrm{~W}, 30 \mathrm{~W}$, and $60 \mathrm{~W}$. The resulting concatenated cells are shown in Figure 3.

It is clearly shown in Figure 3 that some cells in module A are hotter than some other cells while the module generates $6 \mathrm{~W}$ and $30 \mathrm{~W}$. On the other side, module B shows a homogenous distribution at the three points of operation, while module $\mathrm{A}$ has much contrast. It is also easily seen that module B was colder when it worked near the maximum power point; this occurs because only a portion of the total amount of irradiated energy in the module is converted to heat; the rest is supplied to the external load. On the opposite, when the module works in an operation point far from the maximum power point, then the irradiated energy in the module mainly becomes on heat.

It may also be easily seen in Figure 3 that module A contains some cells at a temperature which does not match the cells located around it. It is an alert for a hot spot problem in those cells. Due to this, cells 16 and 25 were chosen as the sample for subsequent tests, where cell 16 represents an abnormal situation and cell 25 exhibits a normal condition. Since these cells are neighbors, both were selected to be captured in a single image.

A DC/DC boost converter was used as the load for the PV modules (Figure 4); this was employed in every developed test in this paper. Since the duty cycle for the converter may be changed as wished, this means that the operation point for the module could be changed as fast as needed.

All measures were made with calibrated equipment, model E-25, of FLIR, with a resolution of $160 \times 120$ pixels, the spectral range of $7.5 \mu \mathrm{m}$ and $13 \mu \mathrm{m}$, and a precision of $\pm 2 \%$. The tests were made by considering more than a single experiment; however, for a matter of simplicity, the reported tests are for just one case.

\section{Thermal Transient}

As mentioned before, cells 16 and 25 were chosen in module A for temperature analysis and characterization data.

First of all, characterization with respect to time was made, because the obtained information for this case should be of transcendental relevance with respect to the characterization for the operating point of the module. It was found in the literature [1] that the temperature of a c-Si module reaches steady state condition until 24 minutes have passed. For analysis purposes, a mc-Si solar cell was employed in this paper, so that more time was considered for the thermal transient characterization.

The first test was developed with a current value of $0.6 \mathrm{~A}$ as operating point for the module, once the thermal equilibrium was reached; the operating point was suddenly changed to a current value of $6 \mathrm{~A}$. The temperature was recorded every minute during a 50-minute period.

A temperature graph for cell 16 is shown in Figure 5(a); it should be observed that although the technique for measuring transient temperature was a little bit different, the behavior during the first 24 minutes is almost the same as that reported in the literature [1]. Although temperature seems to reach its maximum value in approximately 25 minutes, however, the steady state takes more time (see Figure 5(a)). It is worth mentioning that this test was done at midday.

Another test was developed, where the transient was carried out starting from a current value of $6 \mathrm{~A}$ and finishing with a current value of $0.6 \mathrm{~A}$. The temperature graph is illustrated in Figure 5(b); particularly for this case, the recorded time was only for a period of 30 minutes; as it may be observ,ed the curve is very similar to that in Figures 2 and 5 (a) but inverse.

Finally, the temperature evolution for cells 16 and 25 was recorded simultaneously, with an operating point for the 

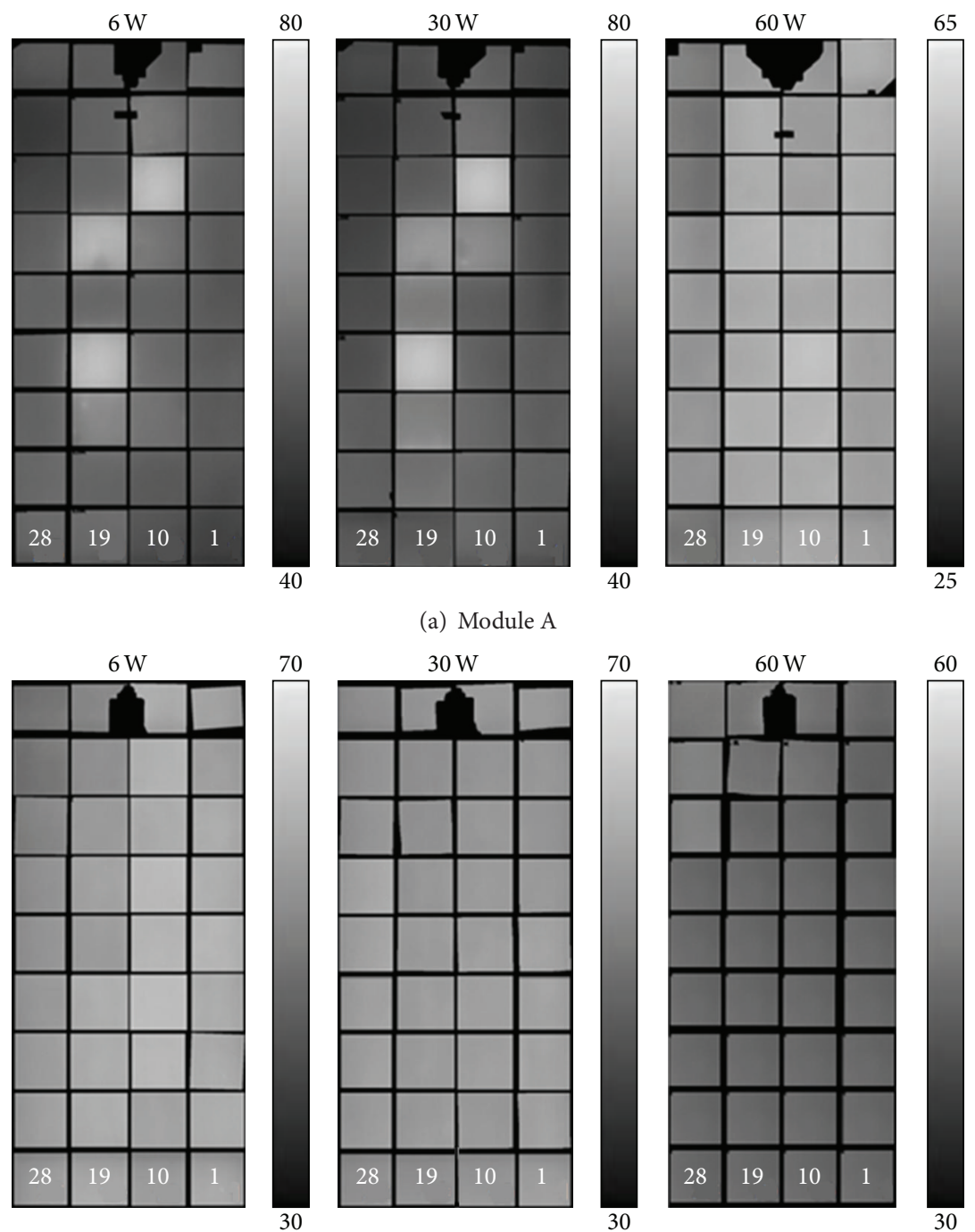

(a) Module A
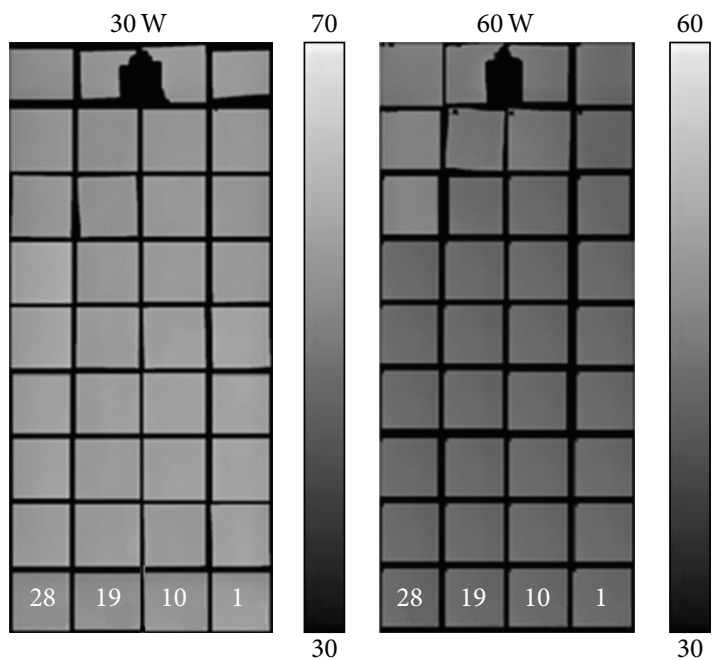

(b) Module B

FIGURE 3: Temperature of two mc-Si modules at three operating points.

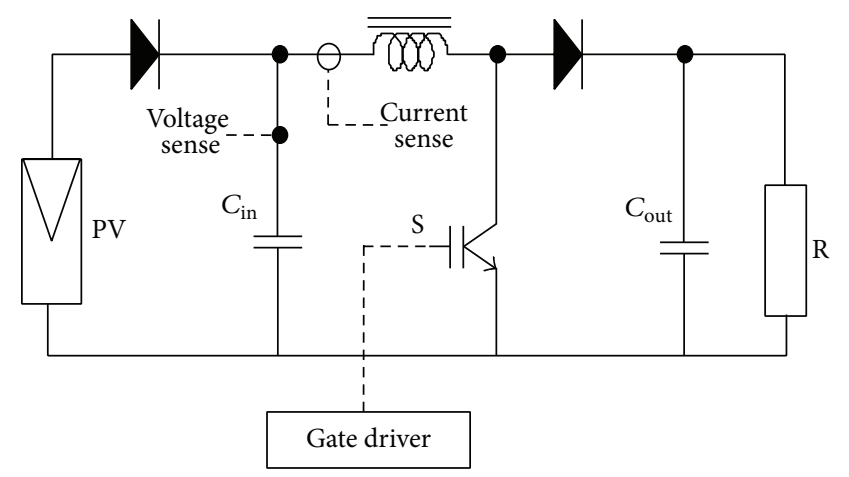

Figure 4: PV panel and power stage.

module by passing from a current of $5 \mathrm{~A}$ to a current of $6 \mathrm{~A}$. Conditions for this test were established in order to analyze if the behavior, which is shown in Figure 5(a), is reproducible in spite of having a lower step change. The resulting curve is illustrated in Figure 6(a).

Some interesting facts are implicitly revealed in this figure. In the first place, the shape of the temperature curve is similar to those obtained before, which means that the behavior of transient temperature does not depend on the step change for the operating point or weather conditions. In the second place, it should be noticed that cell 16 becomes hotter while cell 25 gets colder, under the same current step conditions. This is explained because the presence of hot spots produces mismatch conditions for the cells.

The temperature difference between cells 16 and 25 is shown in Figure 6(b). It may easily be observed how in 10 minutes the cells reach their bigger temperature difference, and later it is kept constant.

According to tests described before, the temperature transient takes around 30 minutes, so that any experiment for characterization should at least wait for 30 minutes between every capture. 


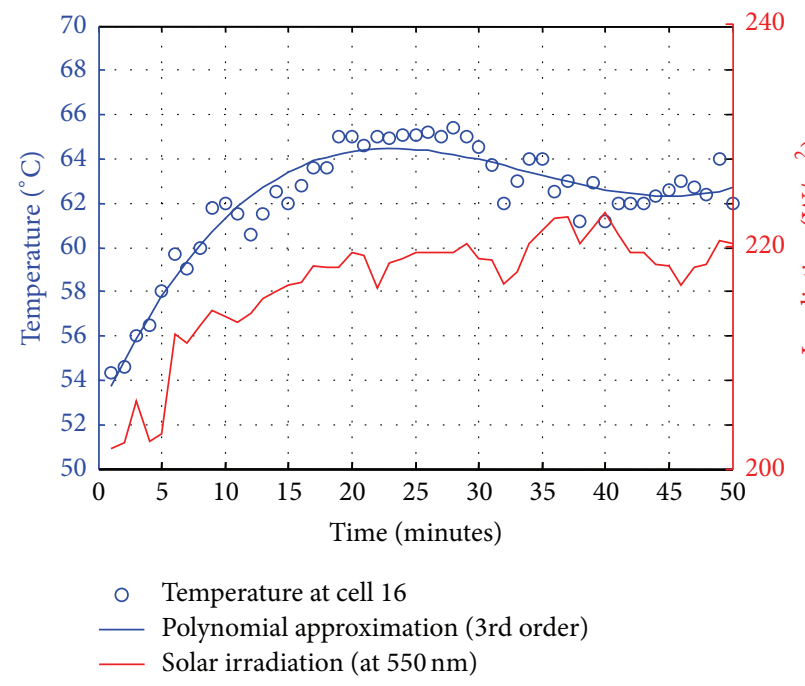

(a)

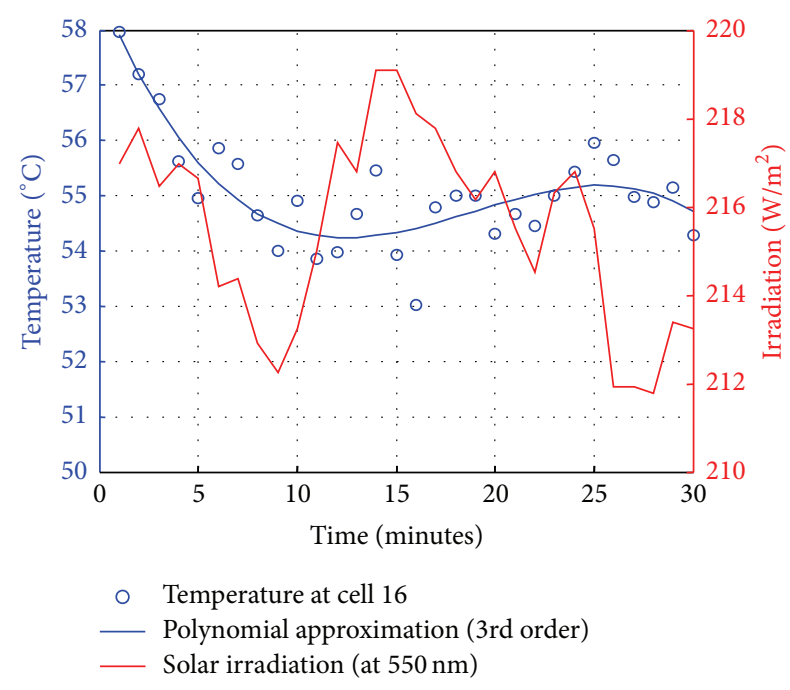

(b)

Figure 5: Thermal transient of cell 16 of module A. (a) For a current step up. (b) For a current step down.

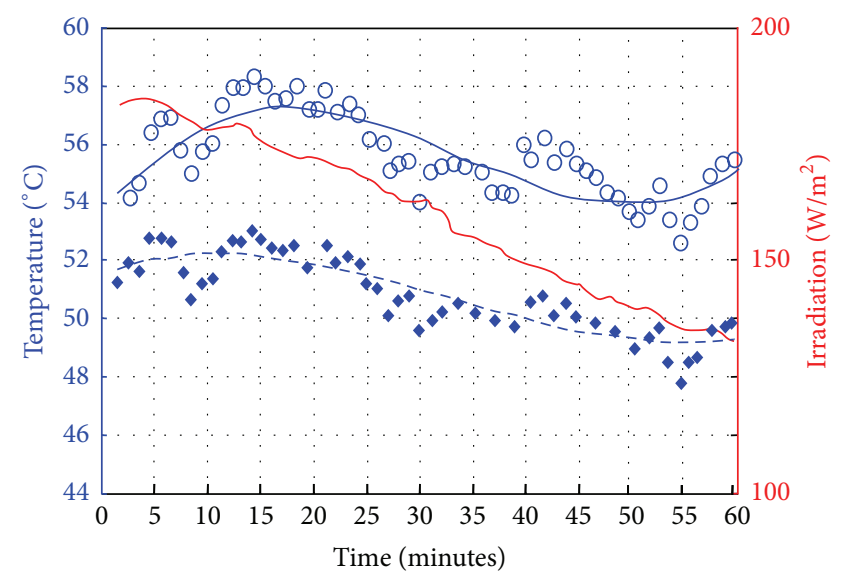

- Temperature at cell 25 Polynomial approximation (3rd order)

○ Temperature at cell 16 - - - Polynomial approximation (3rd order)

— Solar irradiation (at $550 \mathrm{~nm}$ )

(a)

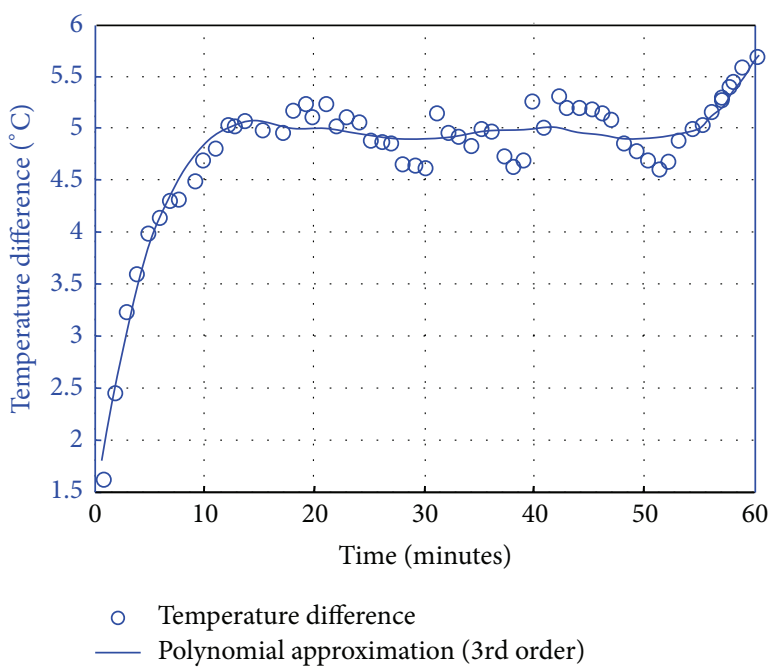

(b)

Figure 6: Thermal transient of screens 16 and 25 of module A. (a) For a small current step up. (b) Temperature difference.

The statistical analysis has an error of \pm 1.3 , for cells 16 and 25 . The difference between both cells was statistically significant $(t=-55-13, \mathrm{df}=59$, and $p=1.85 e-52)$.

\section{Current Characterization}

An analysis for the current was developed as a test in order to obtain the best possible characterization. A period of time of 30 minutes was established in order to let the temperature reach the steady state conditions while the applied current to the module was increased at that period of time.
Unfortunately, changes on weather conditions made it very hard to carry out the tests under exactly the same conditions; however, this factor may be diminished. All the tests were developed from 11:00 a.m. to 4 p.m. in order to minimize the effects due to weather conditions; this procedure certainly meant such a great amount of time in order to be able not only to conclude and validate all cells but also to establish all the possible module defects.

The characterization for the current was done for cells 16 and 25, due to a mismatch found from these cells on previous analysis. The temperature was registered while the module 


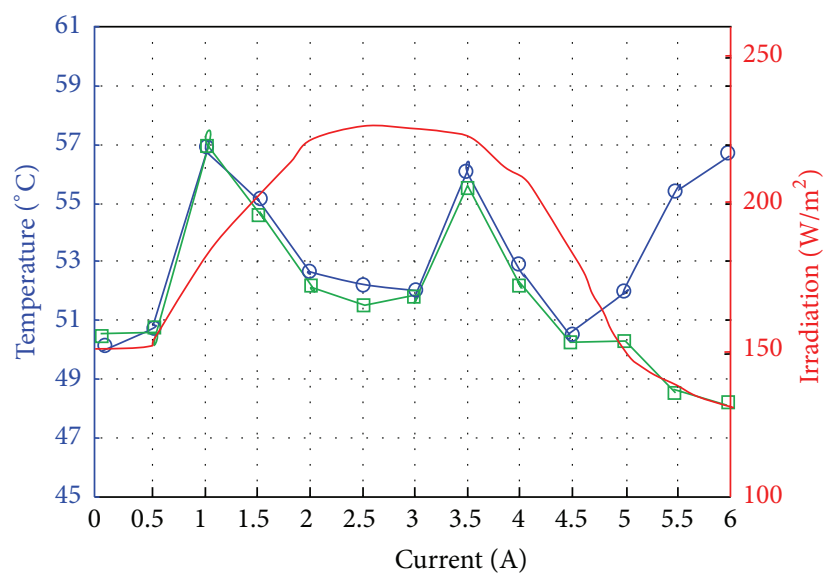

- Solar irradiation (at $550 \mathrm{~nm}) \quad \square$ Temperature at cell 25 ○ Temperature at cell 16

(a)

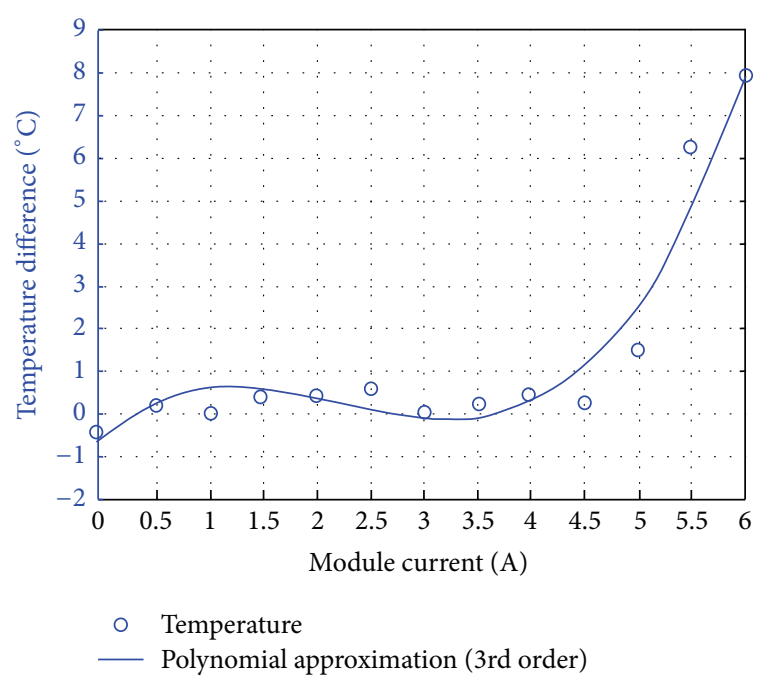

(b)

FIGURE 7: Current characterization under 0.5 A increments: (a) temperature graph and (b) temperature difference.

current was increased every 30 minutes; the starting value for current was at $0.5 \mathrm{~A}$, with step increments of $0.5 \mathrm{~A}$, until $6 \mathrm{~A}$ value was reached. In other words, the duty cycle for the DC/DC boost converter was changed according to the specified current demand. The test began at 11:00 a.m. and finished at 4:00 p.m. It is evident that the reason for this long term of time is due to the restriction of having to wait 30 minutes for every change of load.

Obtained results from the test are illustrated in Figure 7(a); at first sight, it may seem that no relevant information was found. However, very different conclusions may be drawn from the graph.

It is easily seen in Figure 7(a) that there exists more than a minimum value for temperature, so that it may be assumed that there exist multiple maximum power points. This, then, may imply that there may exist partially shaded areas or mismatch conditions at the PV panel. Since the tests were carried out under no shaded areas, it means that a mismatch occurs.

A better look to the graphs allows us to observe that the temperature for cells 16 and 25 suffers an important difference. Very often, these differences are due to weather conditions; however, thier influence should almost be the same on both cells due to the fact of being neighbors, so that a different cause should be considered forward in this particular case.

Data information would be clearer if temperature differences were graphed and compared for both cells (16 and 25). The environmental influence factor is significantly reduced when information is illustrated as it is shown in Figure 7(b). It should also be noticed that, at lower temperature conditions, both cells have almost the same temperature; however, at higher currents, the curves start to deviate from each other since cell 16 becomes hotter and cell 25 becomes colder.

The obtained result, which is illustrated in Figure 6(a), has to be confirmed and validated. For this purpose, the previous test had to be repeated; however, it was run with a current interval of $1 \mathrm{~A}$ at this time. This let us carry out the test in just three hours instead of the six required hours with a step of $0.5 \mathrm{~A}$. Certainly, this represents a lost in curve resolution but shows minor changes due to weather conditions.

A graph for the second test is illustrated in Figure 8(a). It is easily seen that still there are significant variations; however, temperature differences on both cells exhibit similar evolution, as shown in Figure 8(b). Clearly, cell 16 becomes hotter than cell 25 , when current increases. As a consequence, cell 16 has a lower capability for generating power compared to other cells. Finally, it is possible to identify mismatch conditions by measuring the temperature at the back of a PV panel; this would also let us identify manufacture defects.

\section{Conclusion}

The characterization methods and instrumentation for in situ measurements, defect monitoring, and process control and performance are required in order to assure the quality.

A temperature characterization for a mc-Si module with time and current was developed by thermographic analysis. On the one hand, temperature characterization with respect to time made it possible to identify the temperature variations when the operation point changes for the module. On the other hand, temperature characterization with respect to $\mathrm{PV}$ panel current made it possible to establish cell mismatching conditions.

This method may effectively be applied for detecting defects in PV panels and hot spots regions produced by mismatch conditions in electric module features.

The main importance of the defects detection is because the PV panel will have low efficiency, but also multiple maximum power points, and then a concern to the converter and algorithm of the power extraction. 


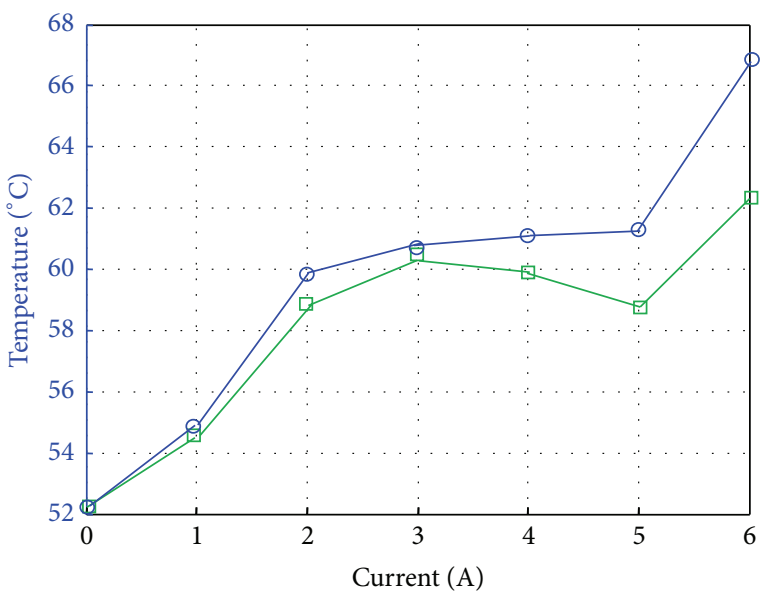

○ Temperature at cell 16

$\square$ Temperature at cell 25

(a)

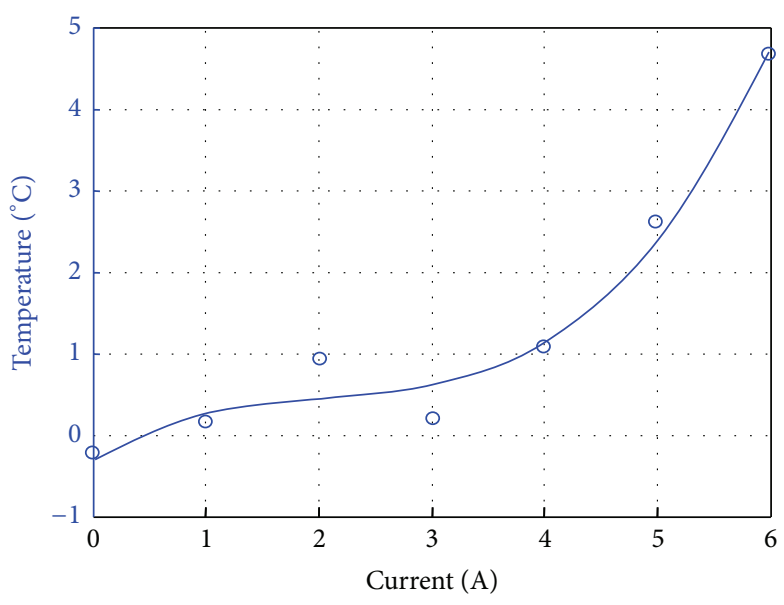

- Temperature difference

— Polynomial approximation

(b)

FiguRE 8: Current characterization under $1 \mathrm{~A}$ increments: (a) temperature graph and (b) temperature difference.

\section{Competing Interests}

The authors declare that they have no competing interests.

\section{References}

[1] D. L. King, J. A. Kratochvil, and W. E. Boyson, “Temperature coefficients for PV modules and arrays: measurement methods, difficulties, and results," in Proceedings of the IEEE 26th Photovoltaic Specialists Conference, pp. 1183-1186, Anaheim, Calif, USA, October 1997.

[2] P. Singh and N. M. Ravindra, "Temperature dependence of solar cell performance-an analysis," Solar Energy Materials and Solar Cells, vol. 101, pp. 36-45, 2012.

[3] C. Deline, "Partially shaded operation of a grid-tied PV system," in Proceedings of the 34th IEEE Photovoltaic Specialists Conference (PVSC '09), Philadelphia, Pa, USA, June 2009.

[4] V. Quaschning and R. Hanitsch, "Numerical simulation of current-voltage characteristics of photovoltaic systems with shaded solar cells," Solar Energy, vol. 56, no. 6, pp. 513-520, 1996.

[5] E. Díaz-Dorado, A. Suárez-García, C. Carrillo, and J. Cidrás, "Influence of the PV modules layout in the power losses of a PV array with shadows," in Proceedings of the 14th International Power Electronics and Motion Control Conference, Ohrid, Macedonia, 2010.

[6] J. W. Bishop, "Computer simulation of the effects of electrical mismatches in photovoltaic cell interconnection circuits," Solar Cells, vol. 25, no. 1, pp. 73-89, 1988.

[7] N. D. Kaushika and A. K. Rai, "An investigation of mismatch losses in solar photovoltaic cell networks," Energy, vol. 32, no. 5, pp. 755-759, 2007.

[8] K. Wilson, D. De Ceuster, and R. A. Sinton, "Measuring the effect of cell mismatch on module output," in Proceedings of the 4th World Conference on Photovoltaic Energy Conference, pp. 916-919, IEEE, Waikoloa, Hawaii, USA, May 2006.

[9] A. M. Gabor, M. Ralli, S. Montminy et al., "Soldering induced damage to thin SI solar cells and detection of cracked cells in modules," in Proceedings of the 21st European Photovoltaic Solar Energy Conference, Dresden, Germany, 2006.

[10] J. W. Bishop, "Microplasma breakdown and hot-spots in silicon solar cells," Solar Cells, vol. 26, no. 4, pp. 335-349, 1989.

[11] J. Bauer, J.-M. Wagner, A. Lotnyk et al., "Hot spots in multicrystalline silicon solar cells: avalanche breakdown due to etch pits," Physica Status Solidi-Rapid Research Letters, vol. 3, no. 2-3, pp. 40-42, 2009.

[12] C. Honsberg and S. Bowden, PVeducation.org, http://www .pveducation.org/pvcdrom/solar-cell-operation/spectral-response.

[13] W. Herrmann, W. Wiesner, and W. Vaaben, "Hot spot investigations on PV modules-new concepts for a test standard and consecuences for module design with respect to bypass diodes," in Proceedings of the Conference Record of the Twenty Sixth IEEE Photovoltaic Specialists Conference, pp. 1129-1132, Anaheim, Calif, USA, 1997.

[14] E. Molenbroek, D. W. Waddington, and K. A. Emery, "Hot spot susceptibility and testing of PV modules," in Proceedings of the 22nd IEEE Photovoltaic Specialists Conference, pp. 547-552, Las Vegas, Nev, USA, October 1991.

[15] V. Quaschning and R. Hanitsch, "Numerical simulation of photovoltaic generators with shaded cells," in Proceedings of the 30th Universities Power Engineering Conference, pp. 583-586, Greenwich, UK, September 1995.

[16] G. Liu, P. Wang, W. Wang, and Q. Wang, "MPPT algorithm under partial shading conditions," in Electrical, Information Engineering and Mechatronics, vol. 1, pp. 91-98, Springer, London, UK, 2011. 

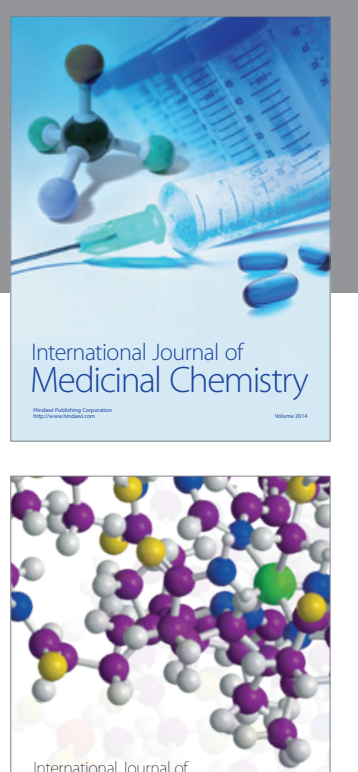

Carbohydrate Chemistry

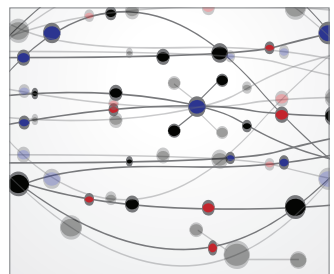

The Scientific World Journal
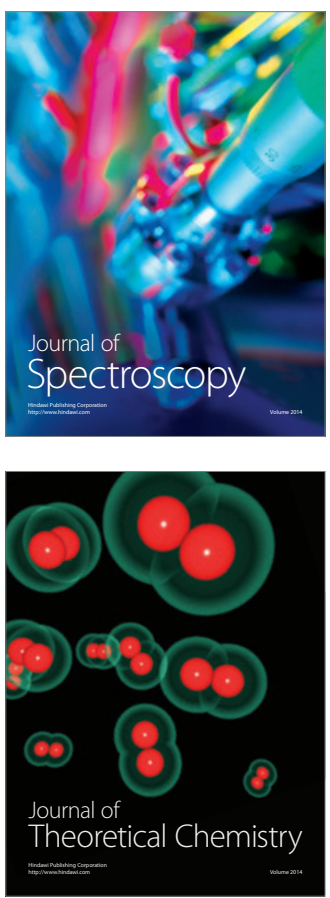
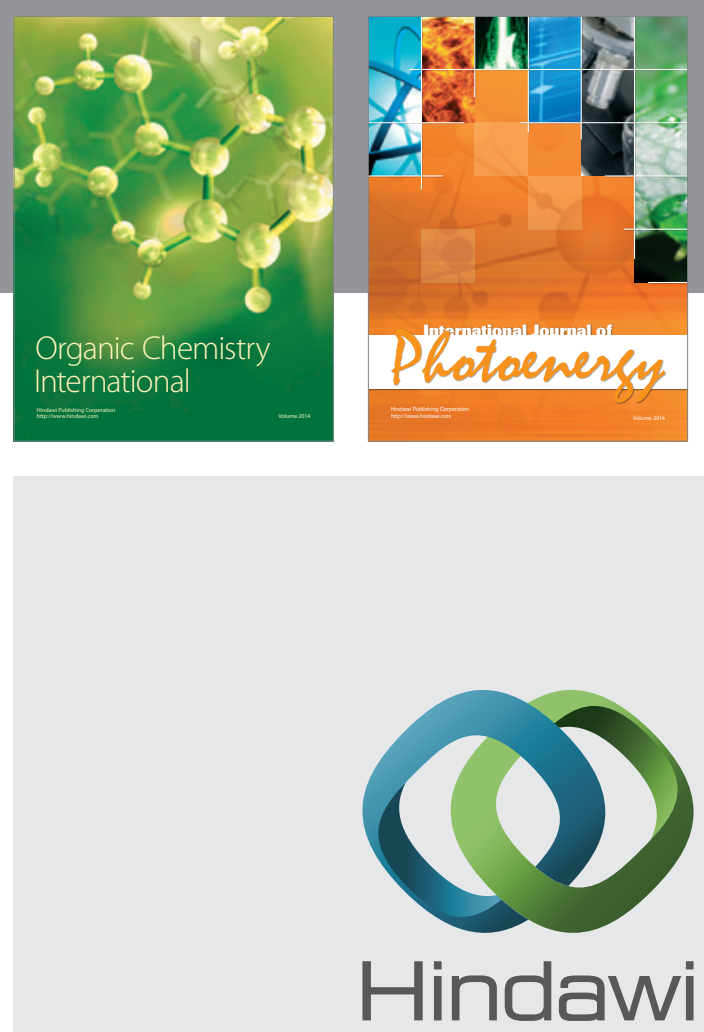

Submit your manuscripts at

http://www.hindawi.com

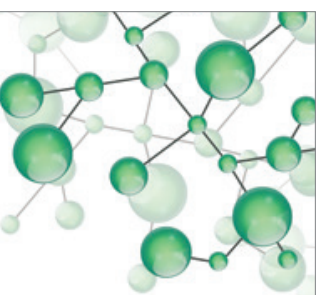

International Journal of

Inorganic Chemistry

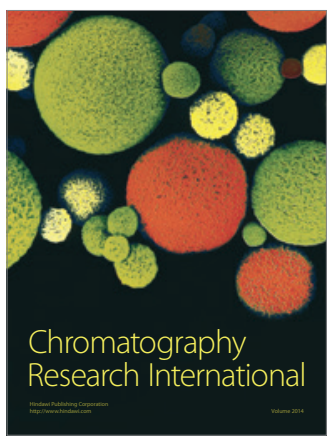

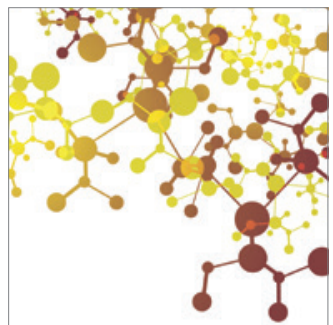

Applied Chemistry
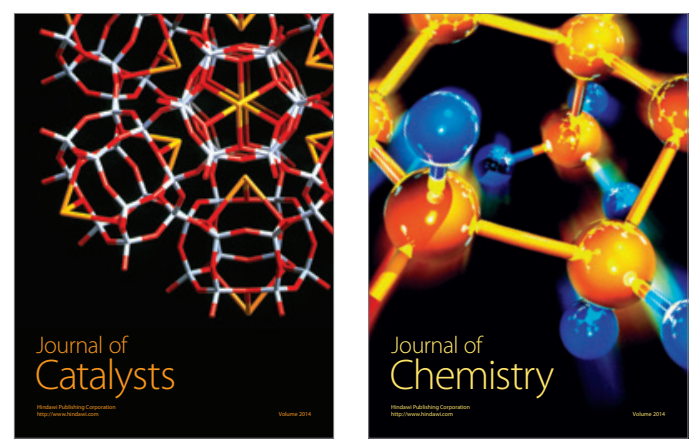
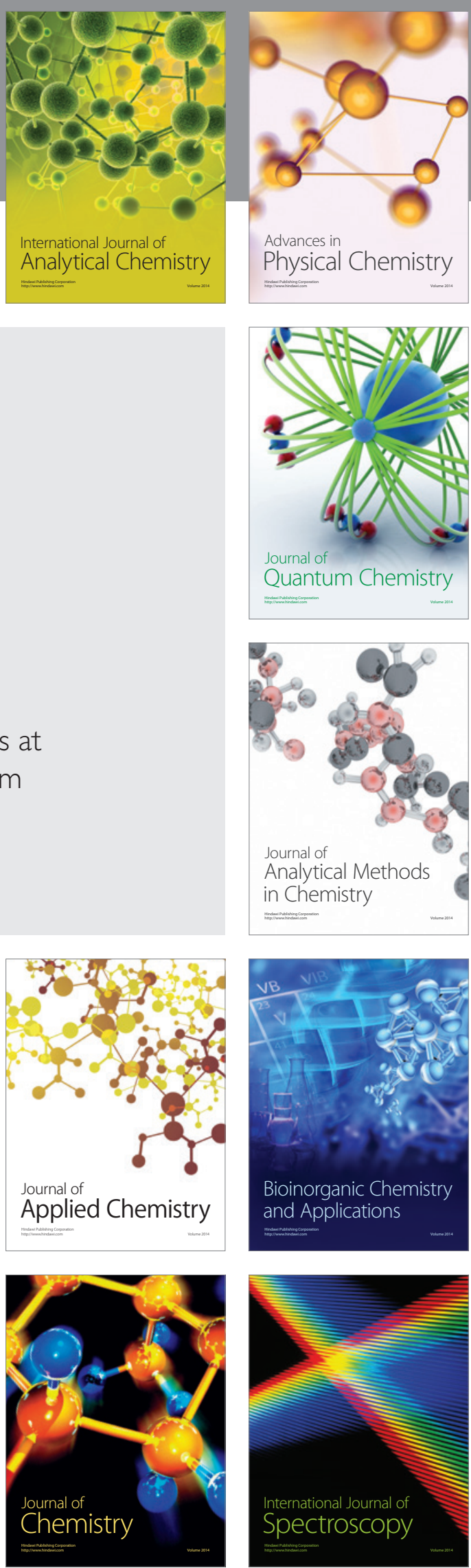